\title{
Research on Distribution Disparity of Tourists in Chinese National Parks
}

\author{
Y.P. Bai \\ School of Geography and Environment, \\ Northwest Normal University, \\ China

\section{L.J. Gu} \\ School of Geography and Environment, \\ Northwest Normal University, \\ China \\ Y.H. Zhang \\ School of Geography and Environment, \\ Northwest Normal University, \\ China
}

\begin{abstract}
This paper takes Chinese National Parks as our sample, which were authorized by China's State Council. By means of GIS and Excel spatial analysis tools and some quantitative analysis methods such as the standard deviation, coefficient of variation, geographic concentration index, attractive model and other indicators to describe tourist scale spatial structure and temporal evolution of the difference in 1991-2009. The result shows that Chinese National Parks in quantity and tourist scale had a lot of growth in 1991-2009; absolute difference increased in fluctuation, relative difference reduced in fluctuation among eight regions; tourist concentration was slow to fall on provinces level.
\end{abstract}

Keywords-tourism management; tourist scale; distribution disparity; Chinese National Parks

\section{INTRODUCTION}

In the 30-odd years sustained development of reform and opening up, Chinese tourism is experiencing the transition from the new economic growth point to pole industry and from the big country to strong country in tourism. China continued to remain the world's fourth largest inbound tourism receiving country in 2007; the WTO forecast in 2020, China will become the world's largest tourist destination [1]. National parks should be managed for both visitor enjoyment and natural and cultural resource protection [2]. National Park is the highest level in Chinese scenic spot system and the most valuable tourism destination [3]. Being the common feature of tourism development in each country of the world, regional difference is the important basis for each country to make its tourism development policy and tactics [4]. Tourist scale is an important index of tourism comprehensive development level. This paper research on distribution disparity of tourists in Chinese National Parks, it helps us to understand tourism development difference pattern and condition.

\section{DATE AND METHODS}

\section{A. Second Level Heading}

This paper takes Chinese National Parks as our sample; its parameter is mainly come from the nearly 19 years of the China Urban Construction Statistical Yearbook. Individual National Park some years' date missing report, Shanghai no scenic spot, will not be included in this study. Chinese National Park is formerly known as the national key scenic spots, and published by approval of the State Council of the People's Republic of China. Since 1982, the State Council announced a total of 7 batches of 208, respectively in 1982 (a total of 44), 1988 (a total of 40), 1994 (a total of 35), 2002 (a total of 32), 2004 (a total of 26), 2005 (a total of 10), 2009 (a total of 21).

\section{B. Research Methods}

This paper absorbs the idea of Development Research Center of the State Council that divides China into eight economic areas, respectively: Northeast China (Liaoning, Jilin, Heilongjiang), the Northern Coastal Areas (Beijing, Tianjin, Hebei, Shandong), the Eastern Coastal Area (Shanghai, Jiangsu, Zhejiang), the Southern Coastal Areas (Fujian, Guangdong, Hainan), the middle reaches of Yellow River (Shanxi, Shaanxi, Henan, Inner Mongolia), the middle reaches of Yangtze River (Hubei, Hunan, Jiangxi, Anhui), Southwest China (Yunnan, Guizhou, Sichuan, Chongqing, Guangxi), Northwest China (Gansu, Qinghai, Ningxia, Tibet, Xinjiang).

The paper uses standard deviation, coefficient of variation, geographic concentration coefficient and tourist concentration coefficient to describe the overall difference of tourist scale in Chinese National Parks, uses attraction model to describe the regional difference structure, and uses ARCGIS software and Lorenz curve to describe the time-space disparity characteristic on provinces level. From the result of the paper, we can put forward the counter measures and suggestions for further development of Chinese National Parks.

\section{DISTRIBUTION DISPARITIES OF TOURISTS IN CHINESE NATIONAL PARKS}

\section{A. The Quantity and Scale of Tourists Change Trend}

Over the past decades, the impacts of tourism have received increasing attention in discourses and studies on related development[5]; however our country tourism development is uneven and the North-South gap continues widening[6]. Chinese National Parks have great differences in geographic conditions, resource strength, and tourist market conditions; tourists also have big differences in regional level. 
During the period of 1991-2009, the number of Chinese National Parks was growing almost three times, increased from 84 to 208, the middle reaches of the Yellow River in quantity increased at least, the Southern Coastal Areas in quantity increased at largest in the eight economic areas; tourist scale had been a great increase, from 164.87 million to 455.80 million; tourist scale were growing almost 10 times in Northwest China, but the proportion of tourist had been the least in the eight economic areas, the results show that Northwest China tourism need to be further development.

The 1991, 2001, and 2009 of Chinese National Parks in quantity and tourist scale with two axis column chart show that (as shown in figure 1), the total amount of Chinese National Parks had been a great increase in each region, especially the past 10 years the rapid growth; in addition to tourists in the Eastern Coastal Areas had the fluctuation, and other areas have got obvious growth, nearly 10 years, tourist scale in the Eastern Coastal Area and Southern Coastal Area were the most rapid growth.

Tourist scale curve profile in Chinese National Parks showed that (as shown in figure 2), during the period of 19912000, tourist scale maintained the stable development in Chinese National Parks; during the period of 2000-2009, tourist scale have rather great development, the total amount of visitors rose quickly, and due to the impact of SARS epidemic, total visitors have a certain fluctuation in 2003.

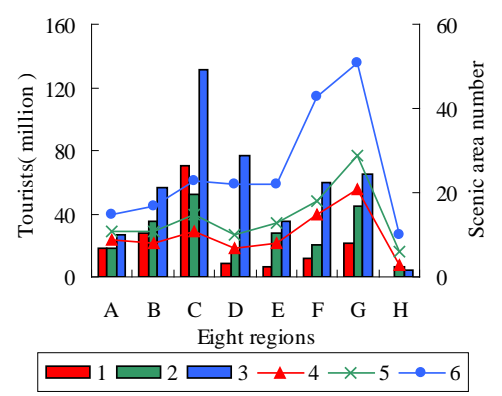

FIGURE I. TOURIST SCALE CHANGES IN CHINESE NATIONAL PARKS

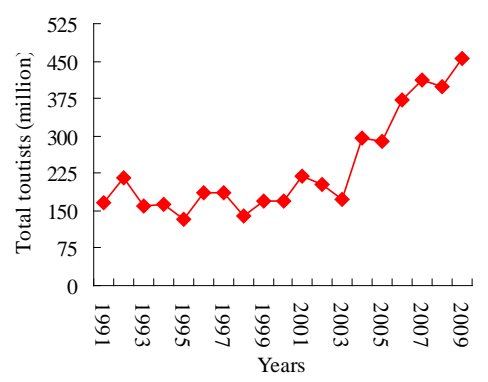

FIGURE II. FIGURE 2: TOURIST SCALE CHANGES IN CHINESE NATIONAL PARKS

Note: A, B, C, D, E, F, G and H represent the eight regions, Northeast China, the Northern Coastal Areas, the Eastern Coastal Areas, the Southern Coastal Areas, the middle reaches of Yellow Rive, the middle reaches of Yangtze River, Southwest China, Northwest China respectively; 1, 2 and 3 represent the number of tourists in 1991, 2001, 2009 respectively; 4, 5 and 6 represent the number of national park in 1991, 2001, 2009 respectively.

\section{B. The Overall Difference of Tourist Scale in Chinese National Parks}

The paper uses standard deviation (VOC) to describe the absolute difference of tourist scale in Chinese National Parks, uses the coefficient of variation $(\mathrm{CV})$ to describe the relative difference of tourist scale, and uses geographic concentration coefficient $(\mathrm{G})$ and tourist concentration coefficient (GP) to measure the distribution of tourists in the provinces.

Geographic concentration coefficient calculation formula is as follows:

$$
G=100 \times \sqrt{\sum_{i=1}^{n}\left(\frac{X_{i}}{T}\right)^{2}}
$$

In the formula, $G$ is geographic concentration coefficient, $X_{i}$ is the number of visitors in the $i$ province, $n$ is the total number of provinces, and $T$ is the total number of tourists received. $G$ between 0 and 100 , the more its value is big, the more tourists distribution is not balanced; on the other hand, the smaller the value is, the more visitors distribution dispersed.

Tourist concentration coefficient is a kind of improvement. When visitors fully average distribution in the provinces, geographic concentration coefficient marked as , calculation formula is as follows:

$$
\bar{G}=100 \times \sqrt{\sum_{i=1}^{n}(1 / n)^{2}}
$$

TABLE I. HE OVERALL DIFFERENCE IN THE SIZE STATUS OF TOURISTS IN CHINESE NATIONAL PARKS.

\begin{tabular}{|c|c|c|c|c|c|}
\hline \multirow{2}{*}{ Years } & \multicolumn{5}{|c|}{ Various indexes } \\
\cline { 2 - 6 } & $V O C$ & $C V$ & $\bar{G}$ & $G$ & $G P$ \\
\hline $\mathbf{1 9 9 1}$ & 2042.47 & 0.9911 & 17.96 & 35.10 & 95.43 \\
\hline $\mathbf{1 9 9 2}$ & 2676.90 & 0.9946 & 17.96 & 35.28 & 96.44 \\
\hline $\mathbf{1 9 9 3}$ & 1965.84 & 0.9856 & 17.96 & 33.81 & 88.25 \\
\hline $\mathbf{1 9 9 4}$ & 2004.24 & 0.9791 & 17.96 & 34.53 & 92.26 \\
\hline $\mathbf{1 9 9 5}$ & 1172.19 & 0.7121 & 17.96 & 29.30 & 63.14 \\
\hline $\mathbf{1 9 9 6}$ & 1792.85 & 0.7651 & 17.96 & 30.60 & 70.38 \\
\hline $\mathbf{1 9 9 7}$ & 2227.67 & 0.9557 & 17.96 & 33.58 & 86.97 \\
\hline $\mathbf{1 9 9 8}$ & 1257.94 & 0.7227 & 17.96 & 29.79 & 65.87 \\
\hline $\mathbf{1 9 9 9}$ & 1687.51 & 0.7902 & 17.96 & 28.56 & 59.02 \\
\hline $\mathbf{2 0 0 0}$ & 1369.42 & 0.6525 & 17.96 & 28.95 & 61.19 \\
\hline $\mathbf{2 0 0 1}$ & 1466.33 & 0.5314 & 17.96 & 27.72 & 54.34 \\
\hline $\mathbf{2 0 0 2}$ & 1479.34 & 0.5877 & 17.96 & 27.88 & 55.23 \\
\hline $\mathbf{2 0 0 3}$ & 1448.15 & 0.6742 & 17.96 & 32.00 & 78.17 \\
\hline $\mathbf{2 0 0 4}$ & 2436.62 & 0.6583 & 17.96 & 27.01 & 50.39 \\
\hline $\mathbf{2 0 0 5}$ & 1978.00 & 0.5503 & 17.96 & 26.61 & 48.16 \\
\hline $\mathbf{2 0 0 6}$ & 3043.36 & 0.6524 & 17.96 & 28.08 & 56.35 \\
\hline $\mathbf{2 0 0 7}$ & 3173.78 & 0.6151 & 17.96 & 27.14 & 51.11 \\
\hline $\mathbf{2 0 0 8}$ & 3281.42 & 0.6602 & 17.96 & 28.12 & 56.57 \\
\hline $\mathbf{2 0 0 9}$ & 3561.57 & 0.6251 & 17.96 & 27.52 & 53.23 \\
\hline
\end{tabular}

Tourist concentration coefficient calculation formula is as follows: 


$$
G P=\frac{G-\bar{G}}{\bar{G}} \times 100
$$

We can work out standard deviation, the coefficient of variation, geographic concentration coefficient and tourist concentration coefficient of tourist scale in Chinese National Parks (see Table 1, unit: ten thousand). Through the table 1 we can know the overall difference of tourist scale in Chinese National Parks. During the period of 1991-2009, the results showed that: (1) Absolute difference increased tendency in fluctuation, but relative difference reduced tendency in fluctuation among eight regions; tourist concentration was slow to fall on provinces level, and visitors' distribution was not balance. (2) From 1991 to 2000, the absolute difference became narrow, standard deviation fell from 2042.47 to 1369.42; from 200 to 2009, the absolute difference had a quickly pull to rise, standard deviation from 1369.42 up to 3561.57. Our results showed that Chinese National Parks were developing gradually, the regional absolute difference reduced gradually; from 2000 to 2009, with the different regional economic base, transportation and tourism resources conditions in different regions, absolute difference quickly widened again. (3) The variation coefficient from 0.9911 fell to 0.6251 , and it is proved that relative difference narrow among eight regions in 1991-2009. (4) From 1991 to 2009, geographic concentration coefficient and tourist concentration coefficient were both slow to fall on provinces level, but they were still higher than average 17.69 and 50; it is proved that visitors' distribution was not balance.

\section{The Regional Difference Structure of Chinese National Park}

Traditionally located in peripheral areas, national parks can represent unique tourist attractions and may therefore serve as rare engines of economic development in otherwise often weak regional economies by attracting spending from outside the region. In China, National Parks of development promote the regional economy of development, but different National Parks of tourists' attraction are different.

In order to quantify and measure National Parks' attraction, the paper, according to a certain formula, graded National Parks. Every National Park was graded, and through the attractive model weighted calculation, we can get the attractive value of National Parks in each region. Its calculation formula is as follows:

$$
A=\sum_{i=1}^{n} X_{i} Y_{i}
$$

In the formula, is the regional attractive value, is the National Park's rank, is the number of National Park in the corresponding rank, is the attraction weight of National Park in the corresponding rank. is the number of the rank.

Through to statistical data in the China Tourism News and the Travel Times, found that each National Park accepted the number of visitors between 500 thousand and 3 million in each year. Based on these results, the paper takes Chinese National Parks divided into seven grades, with scores ranging on a weight scale from 1 to 7 . The number of National Park's visitors is less than 500 thousand weight for 1 point, less than 1 million and greater than 500 thousand weight for 2 points, less than 2 million and greater than 1 million weight for 3 points, less than 3 million and greater than 2 million weight for 4 points, less than 5 million and greater than 3 million weight for 5 points, less than 10 million and greater than 5 million weight for 6 points, greater than 10 million weight for 7 points. In order to contrast Chinese National Park attraction changes in 1991-2009, we select eight years from nineteen years, and take a comparative analysis of the calculation; we get the attractiveness of the regional value of Chinese National Parks (see Figure 3) and the percentage of attractive value in each region (see Figure 4).

After the analysis of the data, we can know that: (1) The total changing trend of National Parks' attraction was growing during 1991-2009, from 204 up to 544, rose by an astonishing 167 percent. The results showed that the provinces are focusing on the development of tourism, the number of Chinese National Parks and competitiveness have been enhanced. (2) During the period of 1991-2009, each regional attraction got a lot of ascension; in addition to Northeast China and Northwest China, other regional attraction value rose to over 100 percent. It is proved that each region had stepped up to support the development of the tourism industry. (3) The attraction of regional differences is still bigger; the strongest attraction of Southwest China is the weakest attraction of Northwest China seven times, indicated that the regional tourism resources, economic base and the location of different factors, resulting in the development of National Parks still have great differences. (4) The larger attraction of Southwest China and the Eastern Coastal Area of the proportion had dropped in each year, separately from $20.10 \%$ and $20.59 \%$ to $19.30 \%$ and $17.10 \%$. It is proved that other regions are actively reducing attraction differences, especially in the middle reaches of Yangtze River.

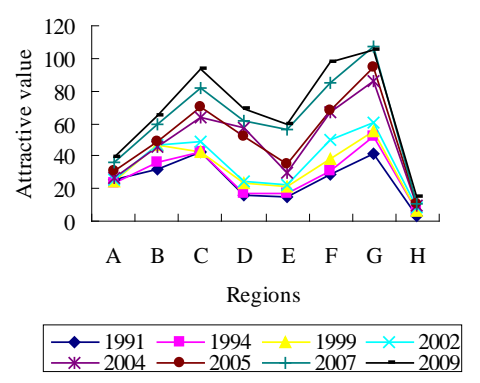

FIGURE III.

THE REGIONAL ATTRACTIVE VALUE OF CHINESE NATIONAL PARKS

Note: A, B, C, D, E, F, G and H representative significance as above. 


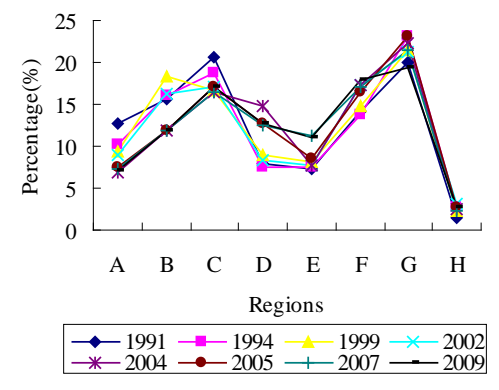

FIGURE IV.

HE PERCENTAGE OF ATTRACTIVE VALUE IN EACH REGION

Note: A, B, C, D, E, F, G and $\mathrm{H}$ representative significance as above.

\section{The Time-Space Disparity Characteristic on Provinces Level}

Contrast the 1991, 2001, and 2009 of tourist scale of Lorenz curve on provinces level (as shown in figure 5). The results showed that: the difference of tourist scale was quite big on provinces level, and had strong spatial clusters in Chinese National Parks. Zhejiang, Jiangsu, Guangdong, Hunan, Liaoning, Beijing, Fujian, Shandong and Hebei of nine provinces make up a large share in 1991, 2001, and 2009, the proportions are $76.10 \%, 57.80 \%$ and $66.88 \%$ respectively. The number of tourist is mainly concentrated in the Yangtze River Delta and Bohai Rim; the Yangtze River Delta takes Jiangsu and Zhejiang as the central, Bohai Rim takes Beijing, Hebei, Shandong and Liaoning as the central. Contrast the 1991 and 2009 of tourist scale in Chinese National Parks, the number of tourist have got obvious increase in all the provinces; In addition to Sichuan Zhejiang Jilin Liaoning Beijing and Heilongjiang, other provincial tourist overall rose to over 100\%; the fastest growth is Ningxia from a smaller base, increased 13 times; the second is Guangdong, increased more than 11 times; Sichuan, Zhejiang, Liaoning and Beijing of four provinces had lower growth rates, mainly because of the big base of the total number of tourists; Jilin and Heilongjiang of tourists scale had less increase, need to be further development. During the period of 1991-2009, Guangdong, Jiangsu and Zhejiang of three provinces had a rapid growth in the total number of tourists, respectively increased by 41.62 million, 33.93 million, and 27.62 million. In recent years, Zhejiang, Jiangsu and Guangdong economic have a great development, tourist scale also continuously improve, the three provinces make up a larger proportion in the eastern and even the national tourist market.

The distribution of tourists in Chinese National Parks profile showed that (as shown in figure 6, the unit: ten thousand): In 2009, tourists concentrated in coastal cities, especially in Zhejiang, Jiangsu and Guangdong, tourists scale respectively for 71.46 million people, 60.24 million people and 45.37 million people, only three provinces total number of tourists is accounted for $38.8 \%$. In 2009, there are nine of the number of tourists received more than ten million, Taihu, the West Lake in Hangzhou, Baiyun Mountain, Guilin and Lijiang River, Gulang Island-Wanshi Mountain Sight, Beidaihe, the
Xin'an and the Fuchun rivers, Wutong Mountain, and Wulingyuan National Park respectively; only the nine National Parks total number of tourists have accounted for $37.1 \%$ of the statistics 203 National Parks total number of tourists. It is proved that tourist scale exist large space differences in Chinese National Parks.

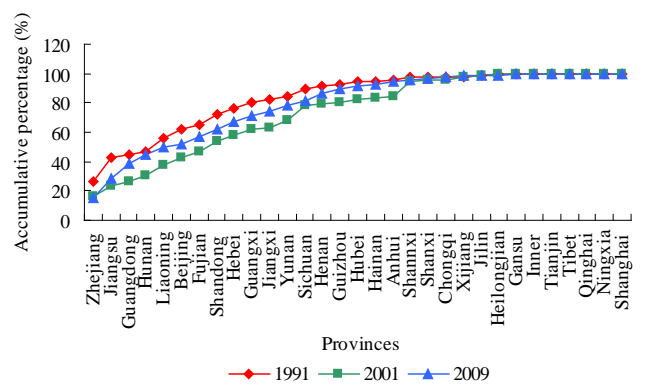

FIGURE V. LORENZ CURVE OF THE DISTRIBUTION OF TOURISTS IN PROVINCES

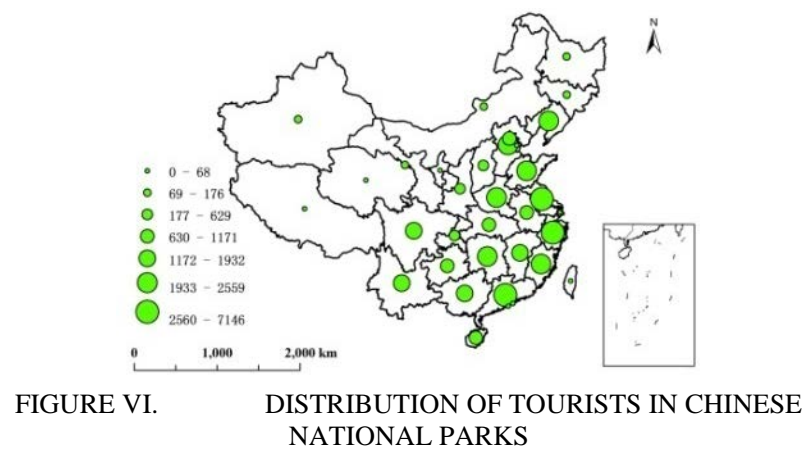

\section{CONCLUSIONS}

Chinese National Parks in quantity and scale of visitors had a lot of growth during 1991 to 2009, but they were a large difference among the eight regions. In general, absolute difference increased tendency in fluctuation, but relative difference reduced tendency in fluctuation among eight regions; tourist concentration was slow to fall on provinces level, and visitors' distribution was not balance. The total changing trend of National Parks' attraction was growing during 1991-2009, each regional attraction got a lot of ascension, but the larger attraction of Southwest China and the Eastern Coastal Area of the proportion had dropped in each year; the attraction of regional differences is still bigger, the strongest attraction of Southwest China is the weakest attraction of Northwest China seven times. The difference of tourist scale was quite big on provinces level, and had strong spatial clusters in Chinese National Parks. Tourists concentrated in coastal cities, especially in Zhejiang, Jiangsu and Guangdong, tourist scale also have large space differences in Chinese National Parks.

\section{ACKNOWLEDGEMENT}

This work was financially supported by the National Science Foundation of China (Grant No.40771054), the Joint Funding Projects of Specialized Research Fund for the Doctoral Program of Higher Education of China (Grant No.20106203110002). 


\section{REFERENCES}

[1] F.J. Liu, J. Zhang, D. D. Chen. The characteristics and dynamical factors of Chinese inbound tourist flow network[J]. Acta Geographica Sinica, 2010, 65 (8):1013-1024. (in Chinese)

[2] Greg Brown, Delene Weber. Public Participation GIS: A new method for national park planning[J]. Landscape and Urban Planning, 2010, 102(1): $1-15$.

[3] C.Q. Li, Z. Wang, B. Qiu, et al. Development of national tourist destination system based on GIS[J]. Science of Surveying and Mapping, 2001, 26 (2):35-38. (in Chinese)

[4] S.M. Xu, M.D. Yang. Reconcrete pattern of regional tourism competitive capability in China[J]. Economy Geography, 2008, 28 (5):876-881. (in Chinese)

[5] Jarkko Saarinen. Traditions of sustainability in tourism studies[J]. Annals of Tourism Research, 2006, 33 (4):1121-1140.

[6] L. Lu, F.L. Yu. A study on the spatial characteristics of provincial difference of tourism economy[J]. Economy Geography, 2005, 25 (3):406-410. (in Chinese) 